\title{
PERAN KESATUAN PENGELOLAAN HUTAN (KPH) DALAM IMPLEMENTASI PERHUTANAN SOSIAL: STUDI DI KPH PRODUKSI KERINCI, PROVINSI JAMBI DAN KPH LINDUNG SIJUNJUNG, PROVINSI SUMATERA BARAT
}

\section{(Roles of Forest Management Unit (FMU) on Social Forestry Implementation: Study on Production FMU Kerinci and Protection FMU Sijunjung}

\author{
Wira Fitria ${ }^{1}$, Didik Suharjito ${ }^{2}$, dan Sulistya Ekawati ${ }^{3}$ \\ ${ }^{1}$ Ilmu Pengelolaan Sumberdaya Alam dan Lingkungan, Fakultas Pascasarjana, Institut Pertanian Bogor, \\ Jl. Lingkar Akademik, Kampus IPB Darmaga, Bogor, 16680, Indonesia; \\ E-mail: wirafitria38@gmail.com \\ ${ }^{2}$ Fakultas Kehutanan IPB, Kampus Fakultas Kehutanan, Institut Pertanian Bogor, Jl. Lingkar Akademik, \\ Kampus IPB Darmaga, Bogor, 16680, Indonesia; \\ E-mail: didiksuharjito@yahoo.com \\ ${ }^{3}$ Pusat Standardisasi Instrumen Ketahanan Bencana dan Perubahan Iklim, \\ Kementerian Lingkungan Hidup dan Kehutanan, Jl. Gunung Batu No.5, Bogor, 16152, Indonesia; \\ E-mail: sulistyaekawati@yahoo.com
}

Diterima 23 Desember 2020, direvisi 24 November 2021, disetujui 29 November 2021

\begin{abstract}
Forest Management Unit (FMU)'s one of the site-level agencies that has information on forest biophysical condition and community socio-culture, so it has a significant role on Social Forestry (SF)'s success. The willingness and role of the FMU in the implementation of the SF program as an organization at the site level needs to be studied, especially from the perspective of the stakeholders involved in the SF. This study examines the role of FMUs to implement Social Forestry (SF) programs through the perspective of the parties involved in $S F$. This role is measured through the attitudes, orientation and actions shift of FMUs towards SF. The research hypothesis is that FMU's roles through attitudes, orientations and actions influence the outcomes of social forestry. The study uses a quantitative approach involving 60 respondents with purpossive sampling, data processing and analysis using a scoring method to see the attitudes, orientations and actions shift and success of SF, and Pearson correlation analysis to confirmed the influence of FMU's roles through attitudes, orientations and actions on SF's success. The results of the study revealed that the attitudes of Production FMU Kerinci and Protection FMU Sijunjung support SF, while the FMUs' actions are based on site specific priorities. Under these conditions the shifting of FMUs attitudes and actions can explain the success of the SF in social and economy field.
\end{abstract}

Keywords: Attitudes; FMU; social forestry; role.

\begin{abstract}
ABSTRAK
Kesatuan Pengelolaan Hutan (KPH) memiliki informasi kondisi biofisik dan sosial ekonomi sekitar hutan sehingga KPH memiliki peranan penting dalam mendukung Perhutanan Sosial (PS). Kesediaan dan peran KPH dalam implementasi program PS perlu dikaji, terutama melalui sudut pandang para pihak yang terlibat dalam PS. Penelitian ini bermaksud mengkonstruksikan dan mengukur pergeseran konseptual pengelola KPH terhadap PS dari sisi pengelola KPH, masyarakat dan pendamping perhutanan sosial berupa sikap dan kelembagaan yang diperlukan dalam pengelolaan perhutanan sosial, mengukur performansi PS di areal KPH serta mengkaji hubungan antara sikap dan perilaku pengelola KPH terhadap keberhasilan PS yang berada di areal KPH. Penelitian dilakukan di 2 lokasi yaitu KPHP Kerinci dan KPHL Sijunjung. Pengolahaan dan analisis data menggunakan metode skoring untuk mengukur sikap, kelembagaan dan keberhasilan PS, serta analisis korelasi Pearson untuk menganalisis pengaruh
\end{abstract}


sikap dan kelembagaan KPH terhadap keberhasilan PS. Fokus penelitian adalah pengukuran sikap dan orientasi KPH terhadap PS, kelembagaan yang telah terbentuk terkait PS di KPH serta keberhasilan PS di areal KPH dari segi sosial, ekonomi dan ekologi. Penelitian ini melibatkan 60 responden dengan purposive sampling hasil penelitian mengungkap bahwa sikap KPHP Kerinci dan KPHL Sijunjung telah mendukung PS, sementara tindakan KPH terhadap PS masih dibatasi oleh kewenangan berdasarkan peraturan perundangan dan keterbatasan pendanaan. Konstruk yang dibangun dapat menjelaskan peran KPH dalam keberhasilan sosial dan ekonomi PS.

Kata kunci: KPH; perhutanan sosial; peran; sikap.

\section{PENDAHULUAN}

Peningkatan peran masyarakat dalam pengelolaan hutan merupakan suatu keniscayaan karena masyarakat merupakan bagian integral dari ekosistem hutan (Darusman, 2002). Beberapa penelitian menunjukkan bahwa pada kondisi tertentu, kelembagaan yang dibangun dan dijalankan oleh masyarakat pengelola hutan menjadi alternatif yang lebih baik dibandingkan peraturan yang dipaksakan dari luar oleh pemerintah ataupun privatisasi pengelolaan hutan (Dietz et al., 2003; Ostrom, 1990). Hal ini sejalan dengan hasil penelitian (Agrawal, 2001) yang menyatakan bahwa fokus yang harus dipahami adalah prinsip-prinsip dalam pengelolaan yang dapat mengarahkan masyarakat untuk mengelola hutan dengan mandiri, sesuai dengan peraturan yang dibangun bersama oleh komunitas. Dalam rangka mencapai kelembagaan yang diharapkan tersebut, terdapat opsi intervensi dari pihak luar yaitu pemerintah, organisasi non pemerintah atau pendamping lainnya (Barnes dan van Laerhoven 2014). Sementara itu Schusser et al. (2015) menyatakan bahwa instansi pemerintah sebagai pengadministrasi, memiliki pengaruh signifikan terhadap keberhasilan Perhutanan Sosial (PS). Di dalam negeri, pendelegasian pelaksanaan skema PS ke tingkat tapak juga dianggap sebagai salah satu skenario yang tepat oleh para pihak (Herawati et al., 2017, Suharjito, 2017).

Menurut Dove (1995) terdapat pilihanpilihan dalam menjalankan intervensi yang efektif terhadap PS, salah satunya adalah dengan mengubah "power relation" atau dengan mengubah sikap terhadap PS. Kesatuan Pengelolaan Hutan (KPH) sebagai salah satu organisasi di tingkat tapak memiliki informasi kondisi biofisik hutan, kondisi sosial budaya masyarakat, potensi dan persoalan, termasuk konflik di dalamnya, sejarah penguasaan lahan, serta siapa yang menguasai lahan (Ekawati, 2014). Oleh karena itu sikap KPH terhadap PS menentukan keberhasilan intervensi pemerintah terhadap pelaksanaan PS. Sebelumnya telah terdapat kajian tentang peran $\mathrm{KPH}$ dalam PS dari segi peraturan perundangan (Sahide et al., 2016) maupun kajian mengenai birokrasi dan perubahan paradigma pengelola hutan dari sudut pandang aparatnya sendiri (Kumar \& Kant, 2005), namun belum terdapat kajian mengenai kesediaan dan peran KPH dalam implementasi program PS, terutama melalui sudut pandang para pihak yang terlibat dalam PS.

Penelitian ini bertujuan untuk mengukur sikap dan orientasi serta kelembagaan $\mathrm{KPH}$ yang diperlukan dalam pengelolaan PS, mengukur keberhasilan PS yang berada di areal $\mathrm{KPH}$, serta menganalisis hubungan antara sikap dan kelembagaan KPH dengan keberhasilan PS di areal KPH.

Hipotesis yang diuji pada penelitian ini adalah pengaruh sikap KPH terhadap kelembagaan KPH terkait PS, serta pengaruh kelembagaan terhadap keberhasilan PS dari segi sosial, ekonomi, dan ekologi. 


\section{METODE PENELITIAN}

\section{A. Kerangka Pikir Penelitian}

Posisi KPH merupakan ujung tombak pengelolaan hutan pada level tapak sehingga sangat memungkinkan bagi $\mathrm{KPH}$ membangun kerja sama yang intensif dengan masyarakat setempat. Potensi sumber daya manusia yang dimiliki KPH juga akan mampu mendayagunakan keahliannya dalam pendampingan masyarakat. Peran $\mathrm{KPH}$ dalam pengelolaan hutan berbasis masyarakat telah dijelaskan oleh Setyarso et al. (2014) dengan dasar teori kolaborasi dari Himmelman (1994). Berbagai peran disematkan pada KPH diantaranya sebagai penggagas: katalis; pemberi asistensi teknis; pembangun kapasitas; fasilitator; dan mitra bagi masyarakat pengelola hutan di kawasan hutan Negara. Berbagai peran tersebut perlu dikonfirmasi dari sisi $\mathrm{KPH}$, salah satunya dapat dilihat dari pergeseran sikap KPH (Dove, 1995) menuju sikap ideal yang telah dirumuskan Campbell (1997).

Penelitian dibatasi pada pengukuran keberhasilan PS berdasarkan sikap dan kelembagaan KPH terhadap PS. Sikap dan tindakan KPH terhadap PS dinilai oleh para pihak yang terlibat dengan KPH dalam pelaksanaan PS. Perhutanan sosial yang dimaksud dalam penelitian ini adalah PS yang berada di hutan Negara dan dikelola oleh masyarakat, sehingga pengelolaan hutan adat dan kemitraan tidak termasuk dalam ruang lingkup penelitian.

Peubah penelitian yang diukur adalah sikap dan orientasi, kelembagaan KPH terkait PS serta keberhasilan PS di areal KP.

\section{B. Lokasi dan Waktu Penelitian}

Penelitian dilaksanakan di KPH Produksi (KPHP) Kerinci dan KPH Lindung (KPHL) Sijunjung pada bulan Agustus sampai dengan September 2018. KPHP Kerinci dan KPHL Sijunjung dipilih menjadi lokasi penelitian karena merupakan KPH yang telah operasional dan mencantumkan PS dalam
Rencana Pengelolaan Hutan Jangka Panjang.

Pada KPHP Kerinci, pengambilan data dari masyarakat dilakukan di Desa Sungai Betung Hilir dan Desa Sukopangkat. Di wilayah KPHL Sijunjung, pengambilan data dari masyarakat dilakukan di Kenagarian Padang Laweh dan Kenagarian Tanjuang Labuah.

\section{Metode Pengumpulan Data}

Pendekatan yang digunakan dalam penelitian ini adalah kombinasi pendekatan kuantitatif dan kualitatif. Teknik pengumpulan dilakukan melalui tiga cara yaitu observasi, Studi kepustakaan dan wawancara terstruktur dan kuesioner dengan respons yang ditentukan dan pertanyaan terbuka.

Data primer dan sekunder dikumpulkan dari Dinas Kehutanan Provinsi Jambi, Dinas Kehutanan Provinsi Sumatera Barat, dan masyarakat pengelola PS di wilayah KPHP Kerinci dan KPHL Sijunjung.

Penarikan sampel pada kedua lokasi penelitian dilakukan dengan metode purposive sampling dengan total responden sebanyak 60 orang. Responden terdiri dari personil $\mathrm{KPH}$ yang memiliki tugas berkaitan dengan PS, anggota masyarakat pengelola PS, staf Dinas Provinsi, dan pendamping PS.

Metode pengukuran sikap yang digunakan dalam penelitian ini adalah metode rating yang dijumlahkan (penskalaan model Likert) yang merupakan metode penskalaan pernyataan sikap dengan menggunakan distribusi respons sebagai dasar penentuan nilai skalanya.

Pengukuran sikap dan orientasi dilakukan pada individu personil Dinas Kehutanan Provinsi terutama personil KPH sebagai UPTD. Sikap dan orientasi diukur dengan menggunakan skala Likert (Mueller, 1986) dengan indikator sebagaimana disajikan pada Tabel 1. Pernyataan berkisar dari yang bersifat favorable (positif) hingga non favorable (negatif).

Indikator kelembagaan KPH dalam implementasi PS disajikan pada Tabel 2. Kelembagan diukur melalui tindakan dan kinerja KPH dalam mengimplementasikan 
Tabel 1 Indikator sikap dan orientasi KPH (dimodifikasi dari konsep Campbell (1997))

Table 1 Indicators of attitude and orientation of FMU (modified from Campbell's concept (1997))

\begin{tabular}{llll}
\hline $\begin{array}{c}\text { Sikap dan orientasi KPH terhadap PS } \\
\text { (FMU's attitude and orientation } \\
\text { towards SF) }\end{array}$ & \multicolumn{3}{c}{$\begin{array}{c}\text { Nilai Pengukuran* } \\
\text { (Scoring values) }\end{array}$} \\
\cline { 2 - 4 } & \multicolumn{1}{c}{$\begin{array}{c}\text { Rendah } \\
\text { (Low) }\end{array}$} & $\begin{array}{c}\text { Sedang } \\
\text { (Medium) }\end{array}$ & $\begin{array}{c}\text { Tinggi } \\
(\text { High })\end{array}$ \\
\hline $\begin{array}{l}\text { Dukungan/Fasilitasi KPH terhadap PS } \\
\text { Sikap KPH terhadap posisi masyarakat } \\
\text { dalam PS }\end{array}$ & $\begin{array}{l}\text { Pengendalian } \\
\text { Penerima manfaat/ } \\
\text { pengguna hutan }\end{array}$ & $\begin{array}{c}\text { Transisi } \\
\text { Transisi }\end{array}$ & $\begin{array}{l}\text { Fasilitasi } \\
\text { Mitra/pengelola hutan }\end{array}$ \\
keputusan terkait PS & Pembuat keputusan unilateral & Transisi & $\begin{array}{l}\text { Pembuat keputusan } \\
\text { partisipatif }\end{array}$ \\
$\begin{array}{l}\text { Sikap KPH dalam proses } \\
\text { Pembangunan PS }\end{array}$ & Diarahkan oleh rencana & Transisi & $\begin{array}{l}\text { Mengutamakan proses } \\
\text { belajar }\end{array}$ \\
$\begin{array}{l}\text { Orientasi KPH dalam pemanfaatan } \\
\text { sumberdaya hutan/pembangunan PS }\end{array}$ & $\begin{array}{l}\text { Orientasi Penerimaan untuk } \\
\text { keuntungan nasional }\end{array}$ & Transisi & $\begin{array}{l}\text { Orientasi sumberdaya } \\
\text { untuk keadilan lokal }\end{array}$ \\
\hline
\end{tabular}

Keterangan (Remarks):

Skala Likert 1-5: Kategori Rendah apabila rata-rata nilai 1.0-2.33), Sedang apabila rata-rata nilai 2.34 - 3.67), dan Tinggi apabila rata-rata nilai 3.68 - 5.0) (Low (average score 1.0-2.33), Medium (average score 2.34-3.67), High (average score 3.685.0))

Tabel 2 Indikator kelembagaan KPH dalam implementasi PS (dimodifikasi dari Campbell 1997 dan Pagdee et al. 2006)

Table 2 FMU institutional indicators in PS implementation (modified from Campbell 1997 and Pagdee et al. 2006)

\begin{tabular}{|c|c|c|}
\hline $\begin{array}{c}\text { Kelembagaan KPH dalam } \\
\text { implementasi PS } \\
\text { (FMU Institusions in the } \\
\text { implementation of SF) }\end{array}$ & $\begin{array}{l}\text { Indikator } \\
\text { (Indicator) }\end{array}$ & $\begin{array}{l}\text { Nilai Pengukuran dari } \\
\text { Rendah-Sedang-Tinggi } \\
\text { (Measurement Value from } \\
\text { Low-Medium-High) } \\
\end{array}$ \\
\hline $\begin{array}{l}\text { Tingkat desentralisasi } \\
\text { kewenangan pembangunan } \\
\text { PS }\end{array}$ & $\begin{array}{l}\text { Pengakuan terhadap masyarakat pengelola hutan } \\
\text { prosedur yang jelas untuk melakukan pengendalian } \\
\text { dan monitoring terhadap PS } \\
\text { Relokasi fungsi-fungsi administratif terkait PS } \\
\text { kepada KPH/masyarakat } \\
\text { Relokasi sumber daya anggaran administrasi } \\
\text { kepada KPH/ otoritas lokal }\end{array}$ & $\begin{array}{l}\text { Sentralisasi/Topdown- } \\
\text { Transisi-Desentralisasi/ } \\
\text { Partisipatif }\end{array}$ \\
\hline Manajemen PS & $\begin{array}{l}\text { Batas-batas sumber daya komunitas / batas fisik } \\
\text { hutan yang didefinisikan dengan jelas } \\
\text { Desain area yang ditunjuk untuk penggunaan } \\
\text { khusus } \\
\text { Personil yang terampil dan berpengalaman dalam } \\
\text { pengelolaan sumber daya secara mandiri } \\
\text { Bentuk bantuan teknis dari KPH pada masyarakat } \\
\text { Kepemimpinan yang kuat dan organisasi lokal } \\
\text { yang efektif dengan sumber daya keuangan dan } \\
\text { manusia yang tersedia }\end{array}$ & $\begin{array}{l}\text { Manajemen terpusat- } \\
\text { Transisi-Manajemen } \\
\text { partisipatif }\end{array}$ \\
\hline Pendanaan PS & $\begin{array}{l}\text { Dukungan dari pemerintah dan lembaga donor } \\
\text { lainnya } \\
\text { Pendanaan mandiri }\end{array}$ & $\begin{array}{l}\text { Anggaran kaku-Transisi- } \\
\text { Anggaran fleksibel }\end{array}$ \\
\hline $\begin{array}{l}\text { Norma yang dijalankan KPH } \\
\text { dalam PS }\end{array}$ & $\begin{array}{l}\text { Keamanan penguasaan sumber daya Kepemilikan } \\
\text { yang jelas untuk menggunakan dan mengelola } \\
\text { sumber daya } \\
\text { Kesesuaian antara biofisik komunitas dan sumber } \\
\text { daya dan batasan sosial } \\
\text { Aturan untuk mengatur penggunaan hasil hutan } \\
\text { baik dalam bentuk formal maupun informal }\end{array}$ & $\begin{array}{l}\text { Aturan untuk menghukum- } \\
\text { Transisi-Penyelesaian } \\
\text { konflik }\end{array}$ \\
\hline
\end{tabular}


PS. Keberhasilan PS pada aspek sosial, ekonomi, dan ekologi diukur dengan indikator dari Schusser et al. (2013). Indikator dari aspek sosial yang diukur adalah akses masyarakat terhadap informasi tentang hutan, pengambilan keputusan, dan akses terhadap lahan hutan dan sumber daya yang ada didalamnya. Indikator dari aspek ekonomi yang diukur adalah produk yang dihasilkan masyarakat, pendapatan masyarakat, dan jenis-jenis pemberdayaan masyarakat. Indikator dari aspek ekologi yang diukur adalah kondisi tegakan dan perubahan luas dan kondisi hutan berdasarkan pengamatan responden.

\section{Metode Pengolahan Data}

Hasil pengukuran sikap individu personil $\mathrm{KPH}$ dan respons masyarakat dan pendamping PS terhadap sikap KPH dalam implementasi PS dianalisis dengan metode skoring. Kelembagaan $\mathrm{KPH}$ terkait implementasi PS serta keberhasilan PS dianalisis secara deskriptif. Analisis hubungan antara peran $\mathrm{KPH}$ dengan keberhasilan PS pada aspek sosial, ekologi dan ekonomi menggunakan metode statistika korelasi Pearson (Walpole, 1995). Nilai variabel yang digunakan dalam perhitungan korelasi ini merupakan hasil perhitungan skor berdasarkan hasil penilaian oleh pihak pemerintah (responden personil KPH dan Dinas Kehutanan Provinsi).

\section{HASIL DAN PEMBAHASAN}

\section{A. Sikap dan Orientasi KPH terhadap PS}

Hasil pengukuran sikap menunjukkan bahwa seluruh KPH mendukung PS, namun terdapat tingkat dukungan yang berbeda-beda antar KPH sebagaimana Tabel 3.

Pada KPHP Kerinci seluruh indikator dinilai tinggi oleh individu personil $\mathrm{KPH}$ yang menunjukkan telah terjadi perubahan konseptual menuju keberhasilan PS sesuai konsep Campbell (1997). Perubahan sikap ini dapat mendorong keberhasilan intervensi PS (Dove, 1995).

Sikap yang sama juga ditunjukkan oleh KPHL Sijunjung, meskipun dengan nilai pengukuran yang lebih rendah pada indikator sikap fasilitasi PS dan sikap proses pengambilan keputusan. Perbedaan sikap ini terjadi karena perbedaan fungsi hutan dominan yang dikelola oleh kedua $\mathrm{KPH}$. KPHL Sijunjung yang mengelola wilayah dengan dominasi hutan lindung bersikap lebih

Tabel 3 Sikap dan orientasi KPH terhadap PS pada KPHP Kerinci dan KPHL Sijunjung menurut para pihak Table 3 FMU's attitude and orientation towards PS at KPHP Kerinci and KPHL Sijunjung according to stakeholders

\begin{tabular}{|c|c|c|c|c|}
\hline \multirow[b]{2}{*}{$\begin{array}{c}\text { Peubah Sikap dan Orientasi } \\
\text { (Variablesof attitude and } \\
\text { orientation) }\end{array}$} & \multicolumn{2}{|c|}{ KPHP Kerinci } & \multicolumn{2}{|c|}{ KPHL Sijunjung } \\
\hline & $\begin{array}{l}\text { Pemerintah } \\
\text { (Government) }\end{array}$ & $\begin{array}{l}\text { Masyarakat } \\
\text { dan ORNOP } \\
\text { (Community } \\
\text { and NGO) }\end{array}$ & $\begin{array}{l}\text { Pemerintah } \\
\text { (Government) }\end{array}$ & $\begin{array}{c}\text { Masyarakat } \\
\text { dan ORNOP } \\
\text { (Community } \\
\text { and NGO) }\end{array}$ \\
\hline Sikap fasilitasi terhadap PS & Fasilitasi & Transisi & Transisi & Transisi \\
\hline $\begin{array}{l}\text { Sikap memposisikan } \\
\text { masyarakat dalam PS }\end{array}$ & Mitra/pengelola hutan & Transisi & $\begin{array}{l}\text { Mitra/pengelola } \\
\text { hutan }\end{array}$ & Transisi \\
\hline $\begin{array}{l}\text { Proses pengambilan } \\
\text { keputusan pembangunan } \\
\text { PS }\end{array}$ & $\begin{array}{l}\text { Pembuat keputusan } \\
\text { partisipatif }\end{array}$ & Transisi & Transisi & Transisi \\
\hline $\begin{array}{l}\text { Sikap belajar KPH dalam } \\
\text { proses pembangunan PS }\end{array}$ & $\begin{array}{l}\text { Mengutamakan proses } \\
\text { belajar }\end{array}$ & Transisi & $\begin{array}{l}\text { Mengutamakan } \\
\text { proses belajar }\end{array}$ & Transisi \\
\hline $\begin{array}{l}\text { Orientasi KPH dalam } \\
\text { pemanfaatan sumberdaya } \\
\text { hutan/ pembangunan PS }\end{array}$ & $\begin{array}{l}\text { Orientasi sumberdaya } \\
\text { untuk keadilan lokal }\end{array}$ & $\begin{array}{l}\text { Orientasi } \\
\text { sumberdaya } \\
\text { untuk keadilan } \\
\text { lokal }\end{array}$ & $\begin{array}{l}\text { Orientasi } \\
\text { sumberdaya } \\
\text { untuk keadilan } \\
\text { lokal }\end{array}$ & Transisi \\
\hline
\end{tabular}


berhati-hati dalam memfasilitasi pemberian izin pengelolaan dalam rangka melindungi keberadaan hutan, termasuk pengelolaan oleh masyarakat. Menurut Kepala KPHP Kerinci, prinsip kehati-hatian yang sama juga dianut oleh KPHP Kerinci dengan tujuan untuk menghindari konflik horizontal yang mungkin terjadi antar masyarakat pengelola lahan hutan. Fungsi hutan yang dikelola menimbulkan perbedaan sikap pada masingmasing KPH, hal ini dikarenakan konsekuensi hukum yang berbeda dalam hal pemanfaatan hasil hutan kayu.

Sikap KPH dalam mendukung PS dapat terlihat dari pengakuan $\mathrm{KPH}$ terhadap keberadaan masyarakat di dalam dan sekitar hutan serta usaha KPH untuk memberikan akses legal terhadap hutan kepada masyarakat. Selain itu juga dilihat dari upaya mendorong masyarakat untuk lebih berdaya serta menghargai kearifan lokal masyarakat sebagai pengelola kawasan (Schusser et al., 2013).

Terdapat perbedaan penilaian sikap KPH terhadap PS oleh stakeholder masyarakat dan organisasi non pemerintah (ORNOP) pendamping PS sebagaimana Tabel 3. Hal ini menunjukkan masih terdapat perbedaan pengetahuan, afeksi dan konasi (Azwar, 2016) antara pemerintah dan masyarakat dalam melihat sikap KPH terhadap PS. Proses pelibatan masyarakat selalu dilakukan oleh $\mathrm{KPH}$, serta terdapat pengakuan dari masyarakat bahwa mereka selalu dilibatkan namun tidak terlalu memahami proses-proses yang dilalui. Menurut beberapa responden, mereka menyerahkan pengambilan keputusan kepada ketua kelompok dan akan mengikuti apapun hasilnya selama lahannya dapat ditanami dengan jenis yang mereka pilih. Personil individu KPH menilai sikap KPH telah memenuhi sikap ideal Campbell (1997), sedangkan sebagian besar sikap KPH menurut masyarakat masih berada pada sikap transisi menuju sikap ideal dalam pengelolaan PS.

\section{B. Kelembagaan KPH dalam implementasi PS}

Hasil pengukuran kelembagaan dan manajemen teknis PS KPH disajikan pada Tabel 4.

Kewenangan terkait PS dari pemerintah pusat kepada $\mathrm{KPH}$ adalah fungsi fasilitasi penyiapan pemberian hak/izin PS, fasilitasi penyusunan perencanaan, serta fasilitasi pengembangan usaha. Fungsi administratif terkait PS serta anggaran terutama penerbitan izin dominan dilakukan oleh pemerintah pusat. Pertemuan dalam rangka konsultasi publik penerbitan izin merupakan domain pemerintah pusat, walaupun dilakukan di wilayah $\mathrm{KPH}$. Kepala KPH Kerinci menyebutnya sebagai "tamu di rumah sendiri".

Setelah terbitnya Undang-undang Cipta Kerja Nomor 11 tahun 2020, terdapat perubahan kewenangan $\mathrm{KPH}$ sebagaimana diatur dalam Peraturan Menteri LHK Nomor 8 Tahun 2021. Terkait peran KPH terhadap PS telah disebutkan secara eksplisit dengan tetap menjalankan fungsi fasilitasi dan koordinasi.

Pada Rencana Pengelolaan Jangka Panjang (RPJP) KPH, KPHP Kerinci dan KPHL

Tabel 4 Kelembagaan dan manajemen teknis KPH pada KPHP Kerinci dan KPHL Sijunjung Table 4 Scoring Results of FMU's Institutions dan Technical Managements

\begin{tabular}{lll}
\hline $\begin{array}{l}\text { Kelembagaan KPH dalam implementasi PS } \\
\text { (FMU'S Institutions in SF Implementation) }\end{array}$ & \multicolumn{1}{c}{ KPHP Kerinci } & KPHL Sijunjung \\
\hline $\begin{array}{l}\text { Tingkat desentralisasi kewenangan } \\
\text { pembangunan PS }\end{array}$ & Transisi & Transisi \\
Manajemen PS & Transisi & Transisi \\
Pendanaan PS & Transisi & Transisi \\
Norma yang dijalankan KPH dalam & Penyelesaian konflik & Penyelesaian konflik \\
pembangunan PS & & \\
\hline
\end{tabular}


Sijunjung telah mencantumkan tentang PS. KPHP Kerinci telah memasukkan PS secara eksplisit dalam sasaran pengelolaan dan mengalokasikan blok pemberdayaan masyarakat seluas 25.054,00 Ha. KPHL Sijunjung memasukkan PS secara eksplisit dalam strategi pengelolaan dan mengalokasikan blok pemberdayaan seluas 15.176,67 Ha. Nilai yang dialokasikan dalam blok pemberdayaan ini berbeda dengan PIAPS. Pada KPHP Kerinci, alokasi blok pemberdayaan lebih besar dari PIAPS yang hanya mengalokasikan seluas 18.000,00 Ha, sedangkan pada KPHL Sijunjung mendapatkan alokasi PIAPS seluas 50.000,00 Ha, jauh lebih besar dari alokasi blok pemberdayaan masyarakat. Pencapaian target luasan hingga akhir tahun 2018 pada KPHP Kerinci seluas 6.325,00 Ha dan pada KPHL Sijunjung 47.000,00 Ha termasuk izin yang telah terbit sebelum penggabungan $\mathrm{KPH}$ dengan Dinas Kehutanan Kabupaten.

Pada awal terbentuk, personil KPH terdiri dari pejabat struktural dan staf yang terbatas. Sejak berlakunya UU Nomor 23 tahun 2014, personil dinas kehutanan Kabupaten dan KPH ditarik menjadi personil Dinas Kehutanan Provinsi, sehingga KPH menjadi UPTD Dinas Kehutanan Provinsi dengan personilnya merupakan gabungan dari dinas Kehutanan Kabupaten dan KPH. Dari segi jumlah personil $\mathrm{KPH}$ mendapatkan tambahan personil yang sangat memadai, namun kapasitas personil masih sangat beragam. Kepemimpinan Kepala $\mathrm{KPH}$ sangat menentukan sikap personil KPH lainnya terhadap PS.

Untuk proses awal pembangunan PS, kedua KPH cenderung sangat bergantung pada anggaran pemerintah pusat. Dalam pelaksanaannya, untuk pemberdayaan masyarakat, KPHP Kerinci cenderung tidak terlalu bergantung pada pemerintah pusat, karena telah mulai mengusahakan anggaran dari donor dan membangun unit usaha. Salah satunya adalah bantuan dari Fauna dan Flora Internasional (FFI) untuk mendirikan rumah produksi di samping kantor KPHP serta usaha mandiri untuk mendirikan unit usaha kafe yang menjadi etalase untuk produk hasil PS masyarakat. Sementara itu, pada KPHL Sijunjung, kelompok tani hutan Putra Harapan mendirikan rumah produksi dengan usaha swadaya.

Pada KPHP Kerinci, Izin Usaha Pemanfaatan Hasil Hutan Kayu pada Hutan Tanaman Rakyat (IUPHHK-HTR) yang diberikan kepada 7 Kelompok Tani Hutan di Desa Sungai Betung Hilir sejak tahun 2013 telah memberikan legalitas pada masyarakat yang mengelola kawasan hutan. Namun masih perlu dilakukan pembinaan terkait hak dan kewajiban pemegang izin. Penerbitan izin tidak membuat masyarakat mengubah pola pengelolaan lahan. Masyarakat melakukan kegiatan berladang dan berkebun pada lahannya seperti biasa sebelum terbit izin. Hal yang diharapkan masyarakat adalah dana bergulir untuk meremajakan tanaman kayu manis. Responden pada KPH Kerinci berharap bibit yang diberikan cukup bibit kulit manis, sedangkan bantuan yang diberikan juga meliputi tanaman hutan seperti surian dan sengon serta tanaman buah seperti manggis dan durian. Dalam prakteknya masyarakat hanya merawat bibit kulit kayu manis. Hal berbeda terjadi di Desa Sukopangkat, masyarakat bersedia menanam tanaman lain dan biasanya ditanam di sekitar halaman rumah dan pembatas lahan.

Dengan target seluas 18.000,00 Ha dari pemerintah pusat dalam waktu 2014 sampai dengan 2019, KPHP Kerinci tetap berusaha untuk memenuhi tahapan pembangunan PS yang benar-benar melibatkan masyarakat. KPHP berhati-hati dengan kondisi riil di lapangan dengan memastikan siapa yang benar-benar menguasai lahan. Dalam proses pembangunan PS, KPH berusaha selalu melibatkan masyarakat. Masyarakat sendiri mengaku selalu dilibatkan namun tidak benarbenar mengerti dengan proses-proses yang harus dilalui. Menurut beberapa responden, mereka menyerahkan urusan pengambilan keputusan kepada ketua kelompok dan akan 
mengikuti apapun hasilnya selama lahan mereka tetap dapat ditanami dengan jenis yang mereka pilih. Ketua kelompok memang lebih sering berhubungan dengan KPHP, sementara KPHP juga mengandalkan ketua kelompok untuk menyampaikan informasi kepada anggota kelompok.

Proses pembangunan kelembagaan PS di KPH masih dalam tahap awal seiring dengan operasionalisasi KPH. Peran KPH adalah untuk menjaga kelembagaan pengelolaan hutan kolektif yang telah ada di dalam masyarakat atau menumbuhkan kelembagaan yang belum terbentuk. Pada tahap awal ini, kedua KPH menganggap penting bagi masyarakat untuk mendapatkan legalitas lahan yang dikelola. Hal ini sejalan dengan berbagai penelitian bahwa keamanan hak properti seperti lahan dan pohon penting untuk keberhasilan PS (Charnley \& Poe 2007; Cronkleton et al., 2012).

\section{Keberhasilan PS}

Hasil pengukuran keberhasilan PS menurut para pihak disajikan pada Tabel 5.

Proses pengajuan izin PS membuka akses masyarakat terhadap informasi terkait hutan dan pengambilan keputusan, walaupun tingkat keterbukaan informasi dan proses pengambilan keputusan bervariasi antar PS. Dengan diperolehnya izin PS, akses terhadap lahan hutan dan sumber daya yang ada didalamnya menjadi legal dan masyarakat dapat memutuskan pengembangan usaha yang akan dilakukan dengan rambu-rambu yang tetap perlu diingatkan oleh KPH.

Produk yang dihasilkan masyarakat pengelola PS di KPH Produksi Kerinci adalah kulit manis dan kopi. Kulit manis menjadi seperti tabungan bagi masyarakat. Kebutuhan mingguan masyarakat rata-rata adalah sekitar Rp500.000,00. Pengembangan usaha yang sedang dilakukan adalah pengolahan biji kopi langsung di masyarakat untuk meningkatkan harga jual. Produk yang dihasilkan masyarakat pengelola PS KPH Lindung Sijunjung di Nagari Padang Laweh adalah gaharu dan karet. Pendapatan rata-rata mingguan berkisar antara Rp60.000,00 hingga Rp360.000,00. Sedangkan produk di Nagari Tanjuang Labuah adalah getah pinus dan karet. Faktor yang sangat mempengaruhi kondisi ekonomi masyarakat adalah harga komoditas, hal ini sesuai dengan pernyataan Pagdee et al. (2006) bahwa pasar memiliki pengaruh terhadap keberhasilan PS, terutama pada komunitas masyarakat yang mengusahakan produk komersial.

Pada KPH Produksi Kerinci, kondisi tegakan kayu manis masih sangat dijaga. Namun juga terdapat tantangan dari kebutuhan lahan untuk pertanian. Di beberapa areal KPH terdapat monokultur kentang dan tanaman pertanian lainnya. Pada KPH Lindung Sijunjung di lokasi Padang Laweh dan Tanjuang Labuah kondisi hutan terjaga

Tabel 5 Keberhasilan PS di KPH menurut para pihak

Tabel 5 Scoring value results of SF's success according to stakeholders

\begin{tabular}{lclll}
\hline \multicolumn{1}{c}{$\begin{array}{c}\text { Bidang Keberhasilan PS } \\
\text { (Variables according to stakeholders) }\end{array}$} & $\begin{array}{c}\text { Kilai } \\
\text { (Value) }\end{array}$ & $\begin{array}{c}\text { Keberhasilan PS } \\
\text { (SF's Success rate) }\end{array}$ & $\begin{array}{c}\text { Nilai } \\
\text { (Value) }\end{array}$ & $\begin{array}{c}\text { Keberhasilan PS } \\
\text { (SF's Success rate) }\end{array}$ \\
\hline Sosial & & & & \\
Instansi Pemerintah & 2,47 & Tinggi & 2,40 & Tinggi \\
Masyarakat dan ORNOP & 2,00 & Sedang & 1,79 & Sedang \\
Ekonomi & & & & \\
Instansi Pemerintah & 2,42 & Tinggi & 1,96 & Sedang \\
Masyarakat dan ORNOP & 2,12 & Sedang & 1,97 & Sedang \\
Ekologi & & & & \\
Instansi Pemerintah & 1,55 & Rendah & 1,76 & Sedang \\
Masyarakat dan ORNOP & 1,14 & Rendah & 1,77 & Sedang \\
\hline
\end{tabular}


dengan baik karena masyarakat memiliki aturan adat yang kuat dalam menjaga hutan.

$\mathrm{KPH}$ memegang peranan penting dalam memberikan dukungan jangka panjang bagi masyarakat, terutama dalam memberikan bantuan teknis berupa pengembangan usaha dan kapasitas masyarakat. Hal senada juga terungkap dari penelitian Baynes et al., (2015) dan Pulhin et al., (2007) yang menyatakan bahwa dukungan pemerintah penting bagi masyarakat pengguna hutan.

\section{Analisis Hubungan antara Peran KPH terhadap Keberhasilan PS}

Berdasarkan data dan respon responden, peran KPH dalam memfasilitasi pengajuan PS dan pengembangan usaha adalah peran yang krusial dalam pembangunan PS. Meskipun KPHP Kerinci memiliki sikap yang sangat mendukung PS (Sikap Fasilitasi), pencapaian target luasan cenderung lebih rendah dari target dibanding dengan KPHL Sijunjung yang sikapnya masih transisi antara pengendalian dan fasilitasi terhadap masyarakat pengelola PS. Hal ini sejalan dengan hasil empiris oleh Fraser et al. (2006) yang menyatakan kondisi lingkungan biofisik yang berbeda akan menyebabkan indikator yang berbeda pula untuk tingkat keberhasilan suatu program. Dengan kondisi lahan di areal KPH yang telah dikuasai masyarakat selama bertahuntahun, KPHP Kerinci harus mengelola risiko terjadinya konflik horizontal antar masyarakat pengelola lahan. Berbeda halnya dengan KPHL Sijunjung yang mengelola hutan negara yang diakui oleh masyarakat seperti di Nagari Tanjuang Labuah, atau hutan negara yang diakui masyarakat sebagai hak ulayat namun dijaga keberadaannya dan diketahui batas-batasnya di Nagari Padang Laweh. Prioritas KPHL Sijunjung adalah memberikan akses legal untuk masyarakat melalui PS. Pada pengajuan Hutan Nagari Padang Laweh, kelompok tani hutan yang mengelola areal hutan negara dengan menanami gaharu belum memahami proses pengajuan Hutan Nagari. Hampir seluruh proses pengajuan dilaksanakan oleh $\mathrm{KPH}$, masyarakat pengelola dilibatkan sebagai formalitas. Korelasi sikap dan orientasi KPH terhadap tindakan yang diambil KPH terkait kelembagaan PS disajikan pada Tabel 6.

Tabel 6 Nilai korelasi peubah sikap dan orientasi KPH dalam implementasi PS dengan kelembagaan KPH Table 6 Correlation value of FMU attitude and orientation variables in the implementation of SF with FMU institutions

\begin{tabular}{|c|c|c|c|c|}
\hline $\begin{array}{l}\text { Peubah sikap dan orientasi } \\
\text { (Variables) }\end{array}$ & $\begin{array}{c}\text { Tingkat } \\
\text { desentralisasi } \\
\text { kewenangan } \\
\text { pembangunan PS } \\
\text { (FMU's actions } \\
\text { regarding } \\
\text { authority for SF } \\
\text { development) }\end{array}$ & $\begin{array}{l}\text { Manajemen PS } \\
\quad(F M U \text { 's } \\
\text { actions in SF } \\
\text { management) }\end{array}$ & $\begin{array}{l}\text { Pendanaan } \\
\text { PS } \\
\text { (Funding } \\
\text { SF) }\end{array}$ & $\begin{array}{c}\text { Norma yang } \\
\text { dijalankan } \\
\text { KPH dalam } \\
\text { pembangunan } \\
\text { PS } \\
\text { (Norms } \\
\text { implemented } \\
\text { by FMU in SF }\end{array}$ \\
\hline \multicolumn{5}{|l|}{ Sikap dan orientasi } \\
\hline Sikap Fasilitasi terhadap PS & -0.073 & -0.44 & 0,24 & -0.55 \\
\hline $\begin{array}{l}\text { Sikap memposisikan masyarakat } \\
\text { dalam PS }\end{array}$ & $0,339^{*}$ & $0,446^{* *}$ & $-0,224$ & $0,498^{* *}$ \\
\hline $\begin{array}{l}\text { Proses pengambilan keputusan } \\
\text { pembangunan PS }\end{array}$ & $0,594^{* *}$ & $0,475^{* *}$ & 0,213 & $0,637^{* *}$ \\
\hline $\begin{array}{l}\text { Sikap belajar KPH dalam proses } \\
\text { pembangunan PS }\end{array}$ & 0,219 & $0,450^{* *}$ & $-0,129$ & $0,524^{* *}$ \\
\hline $\begin{array}{l}\text { Orientasi KPH dalam pemanfaatan } \\
\text { sumberdaya hutan/ pembangunan PS }\end{array}$ & 0,006 & -0.02 & $-0,157$ & $0,359^{*}$ \\
\hline
\end{tabular}

**. Korelasi signifikan pada level 0,01 (**. Correlation is significant at the 0.01 level)

*. Korelasi signifikan pada level 0,05 (*. Correlation is significant at the 0.05 level) 
Sikap KPH terhadap PS mempengaruhi kelembagaan yang dibangun dan dijalankan $\mathrm{KPH}$ dalam implementasi PS, hal ini sejalan dengan teori intervensi PS dari Dove (1995). KPHP Kerinci dinilai oleh individu personil KPH dan Dinas Provinsi telah memiliki sikap positif dalam hal fasilitasi terhadap PS, sesuai dengan sikap ideal menurut Campbell (1997). Sementara itu KPHL Sijunjung dinilai berada pada sikap transisi dari pengendalian menuju fasilitasi. Meskipun KPH telah bersikap positif dalam fasilitasi PS, korelasi sikap fasilitasi $\mathrm{KPH}$ tidak signifikan terhadap tindakan kelembagaan yang diambil KPH dalam implementasi PS. Hal ini dapat dijelaskan oleh keterbatasan kewenangan $\mathrm{KPH}$ dalam hal fasilitasi PS pada saat penelitian dilakukan. Pada tahun 2018 operasionalisasi $\mathrm{KPH}$ belum berjalan secara maksimal karena terjadi transisi dari UPTD Kabupaten menjadi UPTD Provinsi.

Pada masa transisi ini KPHP Kerinci tidak memiliki anggaran $\mathrm{KPH}$ tersendiri, seluruh kegiatan yang memerlukan pendanaan ditentukan oleh Dinas Provinsi, termasuk dalam hal mengeluarkan Surat Tugas untuk turun ke masyarakat. Kewenangan terkait anggaran ini baru diubah pada tahun 2019 dimana KPH memiliki pagu anggaran tersendiri untuk dikelola. Tidak jauh berbeda dengan KPHP Kerinci, meskipun KPHL Sijunjung telah mulai memiliki pagu anggaran tersendiri pada tahun 2018, jumlahnya didominasi oleh belanja operasional kantor dan belanja pegawai. Kondisi kewenangan dan penganggaran ini menjelaskan tidak signifikannya hubungan antara sikap positif $\mathrm{KPH}$ dalam memfasilitasi PS dengan tindakan-tindakan yang diambil KPH terkait kelembagaan PS.

Untuk mengkonfirmasi hubungan antara peran KPH yang dilihat dari kelembagaan $\mathrm{KPH}$ terhadap keberhasilan PS dilakukan analisis menggunakan analisis korelasi Pearson ditunjukkan oleh Tabel 7.

Tingkat desentralisasi kewenangan pembangunan PS memiliki hubungan yang signifikan dengan keberhasilan PS di bidang sosial dan ekonomi. Hal ini terkait dengan pengakuan KPH terhadap keberadaan masyarakat sebagai mitra pengelola hutan dan relokasi fungsi administratif dan pendanaan PS. Untuk mencapai keberhasilan ekologi diperlukan prosedur yang jelas untuk melakukan pengendalian dan monitoring terhadap PS.

Tingkat manajemen PS memiliki hubungan yang sangat signifikan dengan keberhasilan PS disemua bidang, hal ini terlihat dari upaya KPH dalam batas-batas sumber daya komunitas/batas fisik hutan yang didefinisikan dengan jelas (Pagdee et al., 2006) melalui pemetaan partisipatif, mencantumkan desain area dalam RPJP, membagi wilayah dalam

Tabel 7 Nilai korelasi peubah sikap dan kelembagaan dalam implementasi PS dengan keberhasilan PS Table 7 Correlation value of FMU attitude and institutions in the implementation of SF with SF's success

\begin{tabular}{|c|c|c|c|c|}
\hline \multicolumn{2}{|c|}{$\begin{array}{l}\text { Peubah sikap dan kelembagaan } \\
\text { (Variables) }\end{array}$} & $\begin{array}{c}\text { Keberhasilan } \\
\text { Sosial } \\
\text { (Social } \\
\text { Accomplishment) }\end{array}$ & $\begin{array}{c}\text { Keberhasilan } \\
\text { Ekonomi } \\
\text { (Economic } \\
\text { Accomplishment) }\end{array}$ & $\begin{array}{c}\text { Keberhasilan } \\
\text { Ekologi } \\
\text { (Ecology } \\
\text { Accomplishment) }\end{array}$ \\
\hline \multicolumn{5}{|l|}{ Kelembagaan } \\
\hline $\begin{array}{l}\text { Tingkat desentralisasi } \\
\text { pembangunan PS }\end{array}$ & kewenangan & $0,342 *$ & $0,614 * *$ & 0,034 \\
\hline Manajemen PS & & $0,612 * *$ & $0.419 * *$ & $0,425 * *$ \\
\hline Pendanaan PS & & $-0,056$ & .293 & $-0,076$ \\
\hline $\begin{array}{l}\text { Norma yang dijalankan } \\
\text { pembangunan PS }\end{array}$ & $\mathrm{KPH}$ dalam & $0,455 * *$ & $0,424 * *$ & 0,227 \\
\hline
\end{tabular}

${ }^{* *}$. Korelasi signifikan pada level 0,01 (**. Correlation is significant at the 0.01 level)

*. Korelasi signifikan pada level 0,05 (*. Correlation is significant at the 0.05 level) 
blok pemanfaatan, blok pemberdayaan dan blok perlindungan, jumlah SDM yang memadai walaupun kapasitas masih beragam serta kepemimpinan yang kuat.

Pendanaan PS belum menunjukkan hubungan yang signifikan dengan keberhasilan PS, hal ini terlihat dari pendanaan KPH yang masih belum mengelola anggaran secara mandiri dan memadai pada saat penelitian dilakukan.

Untuk menjelaskan hubungan korelasi masing-masing indikator kelembagaan dengan keberhasilan PS, perlu dilihat kesesuaian antara kelembagaan ideal dengan peraturan perundangan terkait PS dan fakta yang dilakukan oleh KPH. Analisis kesesuaian ini disajikan pada Lampiran 1.

\section{KESIMPULAN DAN SARAN}

\section{A. Kesimpulan}

Hasil pengukuran menunjukkan bahwa sikap KPH terhadap PS telah positif. Perubahan sikap individu ini mendorong keberhasilan implementasi PS. Dengan perubahan sikap, proses pelembagaan PS pada KPH menjadi lebih signifikan. Hal ini sejalan dengan salah satu misi utama pembentukan $\mathrm{KPH}$ yang relevan dalam konteks PS adalah meningkatkan perekonomian masyarakat lokal di dalam dan di sekitar areal kerja. Dengan perubahan struktur organisasi dan tata kerja pada awal tahun 2018, $\mathrm{KPH}$ memiliki aset berupa sumber daya manusia yang dapat diberdayakan untuk mendampingi PS pada areal kerjanya. Hasil empiris menunjukkan Sikap Fasilitasi KPH belum signifikan karena kondisi keterbatasan wewenang dalam implementasi PS, padahal peran KPH penting dalam proses pengajuan izin dan pengembangan usaha PS. Dengan keterbatasan pendanaan, KPH berusaha untuk memfasilitasi program PS dengan berbagai kreatifitasnya. Kelembagaan KPH saat pengukuran dapat menjelaskan keberhasilan PS dari segi sosial yaitu terbukanya akses masyarakat terhadap informasi terkait hutan, pengambilan keputusan dan akses terhadap lahan hutan dan sumber daya.

\section{B. Saran}

Fungsi fasilitasi KPH dalam pembangunan PS perlu diperkuat dengan memanfaatkan potensi sumber daya manusia yang telah memadai dari segi jumlah personil serta dukungan pendanaan. Penguatan berupa peningkatan kapasitas SDM dapat dilakukan secara intern dengan melakukan pelatihan serta alih teknologi dari personil $\mathrm{KPH}$ yang telah diakui secara nasional ataupun di tingkat Provinsi serta dukungan ekstern dari Kementerian Lingkungan Hidup dan Kehutanan (KLHK). KLHK perlu melakukan penguatan kapasitas personil KPH untuk melakukan fungsi pendampingan masyarakat (mediasi konflik, pemberdayaan masyarakat serta pelatihan teknis lainnya yang relevan). Terkait Peraturan Menteri LHK Nomor 8 Tahun 2021 dalam hal permohonan Perizinan Berusaha Pemanfaatan Hutan, disarankan agar Gubernur tetap melibatkan KPH dalam memberikan pertimbangan teknis terutama terkait informasi potensi Pemanfaatan Kawasan, jasa lingkungan dan HHBK, serta keberadaan masyarakat setempat yang berada di dalam areal yang dimohon.

Selain itu perlu dilakukan penelitian lanjutan tentang peran KPH dalam implementasi PS pada Provinsi yang telah mendapatkan pelimpahan wewenang dalam menerbitkan izin PS dari Pemerintah Pusat.

\section{UCAPAN TERIMA KASIH \\ (ACKNOWLEDGEMENT)}

Ucapan terima kasih disampaikan kepada personil KPHP Kerinci, KPHL Sijunjung, Dinas Kehutanan Provinsi Jambi, Dinas Kehutanan Provinsi Sumatera Barat, KKI Warsi Jambi dan Sumatera Barat, serta pengelola Hutan Sosial di Desa Sungai Betung Hilir, Desa Sukopangkat, Kenagarian Padang Laweh, dan Kenagarian Tanjuang Labuah yang telah bersedia menjadi responden dan narasumber penelitian, juga kepada Mitra 
Bestari yang telah memberikan saran untuk perbaikan tulisan ini.

Ucapan terima kasih juga disampaikan kepada Lembaga Pengelola Dana Pendidikan (LPDP) yang telah mendanai penelitian sehingga tulisan ini dapat terwujud.

\section{DAFTAR PUSTAKA}

Agrawal, A. (2001). Common property institutions and sustainable governance of resources. World Development, 29(10), 1649-1672. https://doi. org/10.1016/S0305-750X(01)00063-8.

Barnes, C., \& van Laerhoven, F. (2015). Making it last? Analysing the role of NGO interventions in the development of institutions for durable collective action in Indian community forestry. Environmental Science and Policy, 53, 192-205. https://doi.org/10.1016/j. envsci.2014.06.008.

Baynes, J., Herbohn, J., Smith, C., Fisher, R., \& Bray, D. (2015). Key factors which influence the success of community forestry in developing countries. Global Environmental Change, 35, 226-238. https://doi.org/10.1016/j. gloenvcha.2015.09.011.

Campbell, J. (1997). Reconciling the Power to Control with the Need to Use : New Perspective for World Forestry (p. 1997). World Commision on Forest and Sustainable Development.

Chokkalingam U, Pulhin JM, Carandang AP, Lasco RD (2006). Conclusions and Recommendations. One Century of Forest Rehabilitation in the Phillipines: Approaches, Outcomes and Lessons. Centre for International Forestry Research, Bogor, Indonesia, pp. 122-132

Cronkleton, P., Pulhin, J. M., \& Saigal, S. (2012). Comanagement in Community Forestry: How the Partial Devolution of Management Rights Creates Challenges for Forest Communities, 10(2), 91-102. https://doi.org/10.4103/09724923.97481

Darusman, D. (2002). Pembenahan Kehutanan Indonesia. Fakultas Kehutanan IPB.

Dietz T, Ostrom E, Stern PC. (2003). The struggle to govern the commons. Science, 302(5652), 1907-1912.

Dove, M. R. (1995). The theory of social forestry intervention: the state of the art in Asia The theory of social forestry intervention: the state of the art in Asia. Agroforestry System, 30, 315-340. https://doi.org/10.1007/ BF00705217.
Ekawati, S. (2014). Pembangunan KPH di Indonesia. In S. Ekawati \& B. Hernowo (Eds.), Operasionalisasi Kesatuan Pengelolaan Hutan ( KPH ): Langkah Awal Menuju Kemandirian. Yogyakarta: PT Kanisius.

Fraser, E. D. G., Dougill, A. J., Mabee, W. E., Reed, M., \& Mcalpine, P. (2006). Bottom up and top down: Analysis of participatory processes for sustainability indicator identification as a pathway to community empowerment and sustainable environmental management. Journal of Environmental Management, 78, 114-127. https://doi.org/10.1016/j. jenvman.2005.04.009.

Herawati, T., Liswanti, N., \& Banjade, M. R. (2017). Merancang Masa Depan Perhutanan Sosial di Provinsi Lampung Dari skenario menuju aksi. Brief CIFOR, (183), 1-8. https://doi. org/10.17528/cifor/006558.

Kumar, S., \& Kant, S. (2005). Bureaucracy and new management paradigms : modeling foresters' perceptions regarding community-based forest management in India. Forest Policy and Economics, 7, 651-669. https://doi. org/10.1016/j.forpol.2004.02.001.

Mueller DJ (1992). Measuring Social Attitudes. New York : Columbia University.

Ostrom, E. (1990). Governing the Commons:The Evolution of Institutions for Collective Action (First Edit). Cambridge: Cambridge University Press.

Pagdee, A., Kim, Y., Daugherty, P. J., \& Kim, Y. (2006). Society \& Natural Resources: An What Makes Community Forest Management Successful : A Meta-Study From Community Forests Throughout the World What Makes Community Forest Management Successful : A Meta-Study From Community Forests Throughout the World. Society \& Natural Resources, 19(1), 33-52. https://doi. org/10.1080/08941920500323260.

Pulhin JM, Inoue M, Enters T. (2007). Three decades of community-based forest management in the Philippines : emerging lessons for sustainable and equitable forest management. Int.For. Rev.,9 (4): 865-883.

Sahide, M. A. K., Supratman, S., Maryudi, A., Kim, Y. S., \& Giessen, L. (2016). Decentralisation policy as recentralisation strategy: forest management units and community forestry in Indonesia. International Forestry Review, 18(1), 78-95.

Schusser, C., Deutsche, D. F. S., Gmbh, F., Forest, G., Consulting, S., Forest, C., ... Schusser, C. (2013). The Applicability of the German Community Forestry Model to Developing 
Countries. Forstarchiv, 84, 24-29. https://doi. org/10.4432/0300-4112-84-24.

Schusser, C., Krott, M., Movuh, M. C. Y., Logmani, J., Devkota, R. R., Maryudi, A., ... Bach, N. D. (2015). Forest Policy and Economics Powerful stakeholders as drivers of community forestry - Results of an international study. Forest Policy and Economics, 58, 92-101. https:// doi.org/10.1016/j.forpol.2015.05.011

Setyarso, A., Djajono, A., Nugroho, B., Wulandari, C., Suwarno, E., Kartodihardjo, H., \& Sardjono, M. A. (2014). Strategi Pengembangan KPH dan Perubahan Struktur Kehutanan Indonesia. e-Book. Retrieved from www. forclime.org
Suharjito, D., Khan, A., Djatmiko, W., Sirait, M., \& Evelyna, A. (2000). Karakteristik Pengelolaan Hutan Berbasis Masyarakat. Pustaka Kehutanan Masyarakat.

Suharjito D. (2017). Kesatuan Pengelolaan Hutan $(K P H)$ : Kebijakan, Implementasi dan Masa Depan. Jakarta: MFP \& Dewan Kehutanan Nasional.

Walpole, RE (1995). Pengantar Statistika. Jakarta: Gramedia Pustaka Utama 


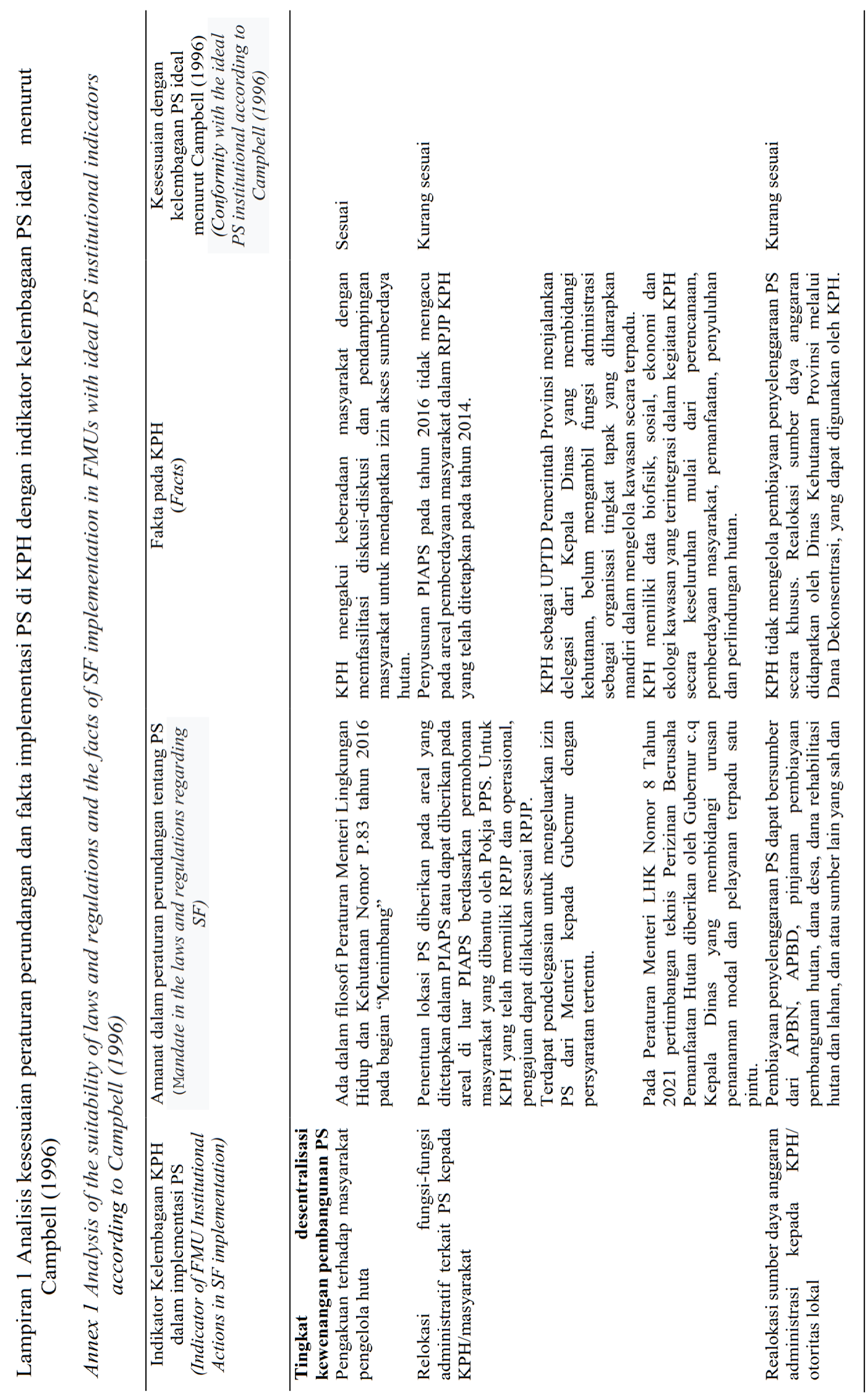




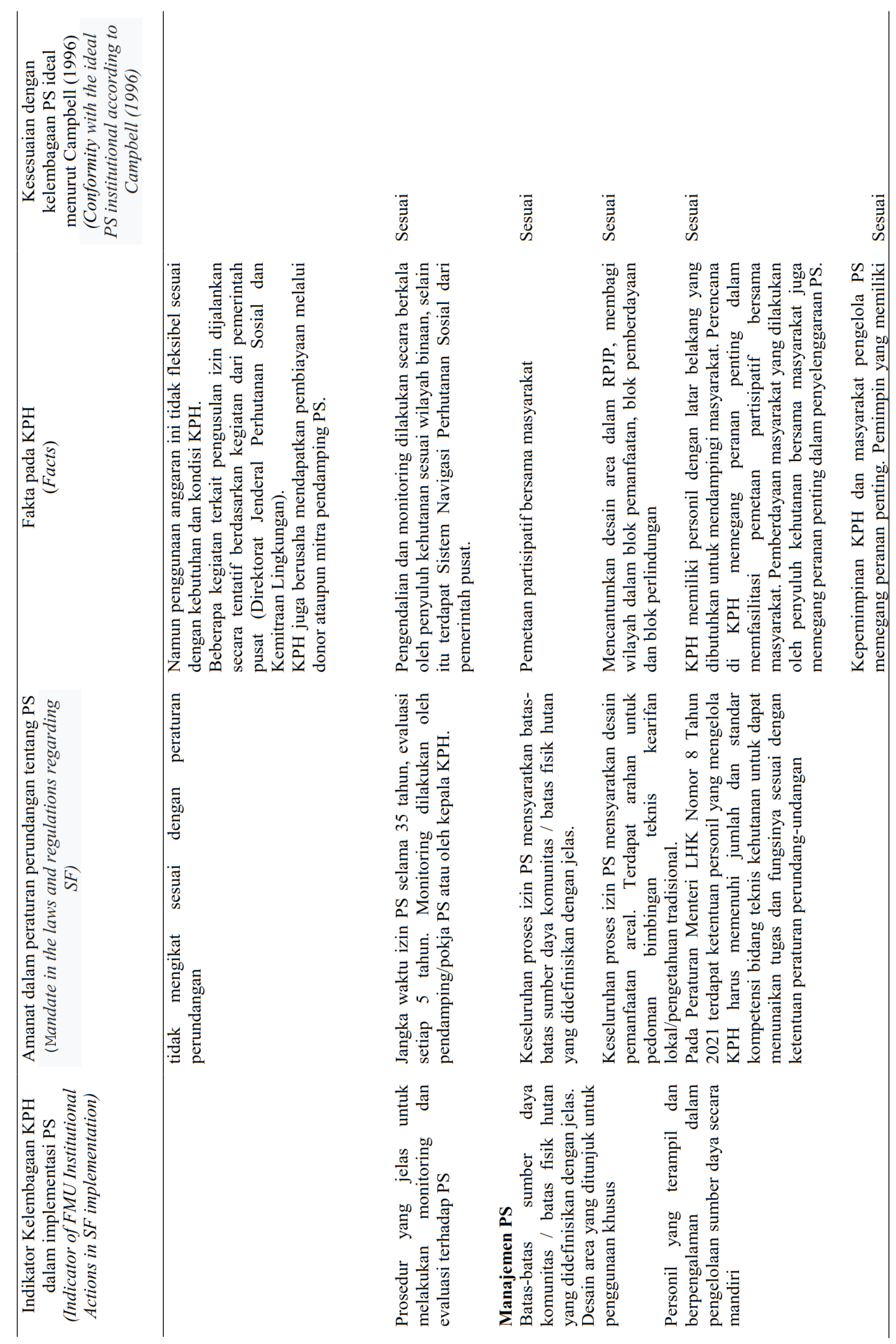




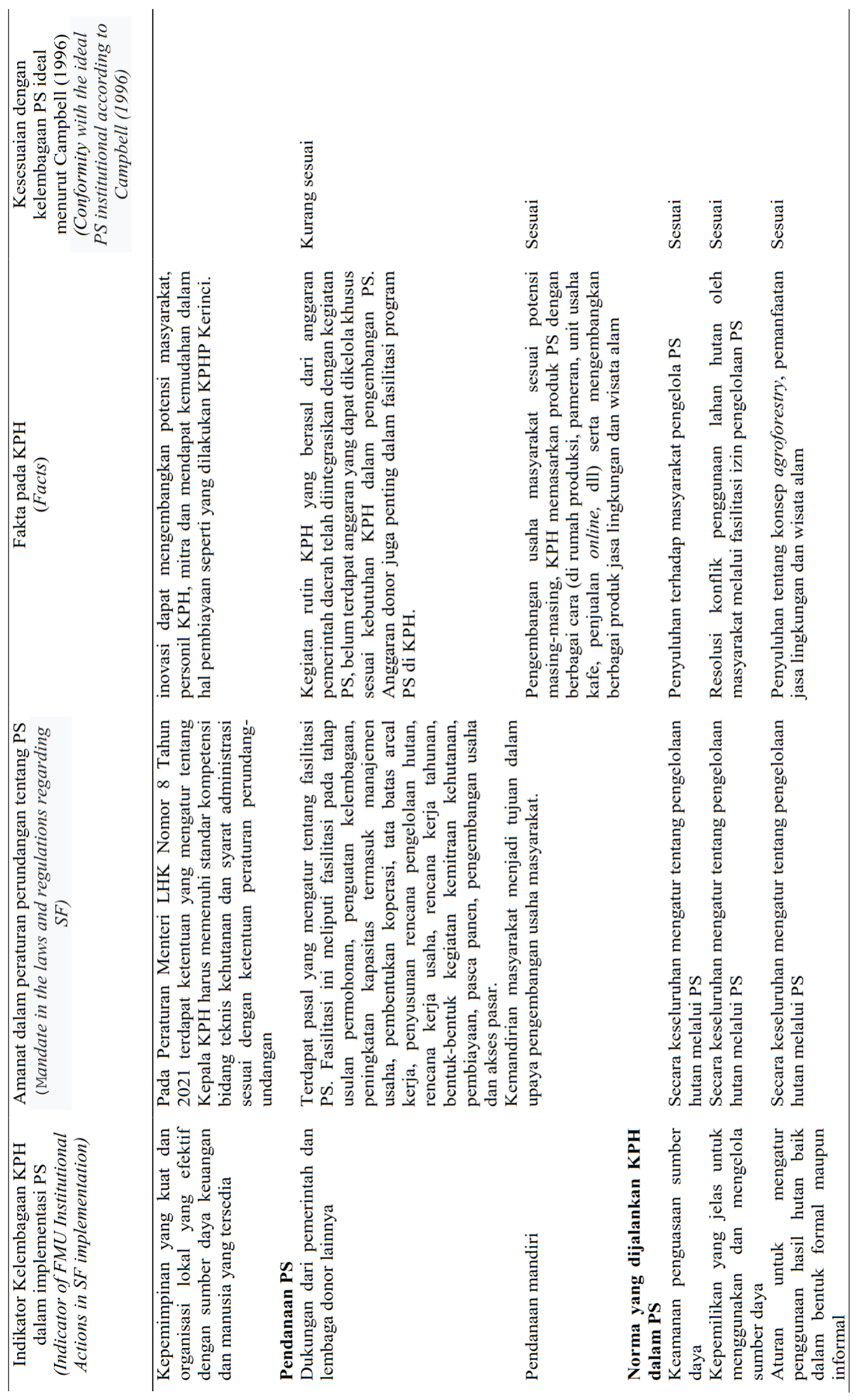

